\title{
Effect of off-Loading Device in Diabetic Foot Ulcer Healing -A Randomized Control Study.
}

\author{
Dr.T.Arun ${ }^{1}$, Dr.Praveen.C.B ${ }^{2}$, Prof.Dr.C.P.Ganesh Babu ${ }^{3}$, \\ Prof.Dr.Robinson Smile ${ }^{4}$ \\ ${ }^{I}$ (Department Of General Surgery, Mahatma Gandhi Medical College \& Research \\ Institute, India) \\ ${ }^{2}$ (Department Of General Surgery, Mahatma Gandhi Medical College \& Research \\ Institute, India) \\ ${ }^{3}$ (Department Of General Surgery, Mahatma Gandhi Medical College \& Research \\ Institute, India) \\ ${ }^{4}$ (Department Of General Surgery, Mahatma Gandhi Medical College \& Research \\ Institute, India)
}

\begin{abstract}
Foot ulcers are the major problems in Diabetic patients. One of the factors which prevent healing of plantar ulcer is pressure on the ulcer. The aim of present study is to find out aoff loading device, which is cheap and comfortable to the patient.

50 ambulant diabetic patients with foot ulcer treated in tertiary care centre, Pondicherry, between October 2010 to March 2012 were included in this study.The patients were randomized into two groups. One was Offloaded and other Not Off-loaded, by draw of lots. Mandakini device was used for off-loading. Patients were followed up at 2,4 and 6 weeks intervals, to assess healing rate of ulcers. Both groups were similar in demographic data and clinical features. In ulcers $<5$ sq.cm the healing rate at 6 weeks was $100 \%$ in all offloaded patients.In ulcers between 5 to 10 sq.cm the healing was $100 \%$ in 13 off-loaded patients at 6 weeks.In>11 sq.cm ulcers, the healing rate was 100\% in 2 off-loaded patients at 6 weeks.Overall the healing was $100 \%$ in $18(72 \%)$ off-loaded patients and $100 \%$ in only $7(28 \%)$ not off-loaded patients and the difference was statistically significant ( $P$ value- 0.0460).Simple off-loading Mandakini technique improves significantly the healing rate of plantar foot ulcer in Diabetic patients.
\end{abstract}

Keywords:Diabetic plantar ulcer,Mandakini device, Off loading,Ulcer healing.

\section{Introduction}

Foot ulcers are the major complications of diabetes mellitus patient and 15\% develop foot ulcers during their life time. If untreated they end in lower extremity amputation and $85 \%$ of non-traumatic lower extremity amputations are due to diabetic foot. The high prevalence of diabetes mellitus in India is 5\% in urban and 1 to $1.5 \%$ in rural and thereby 60 million feet are at risk. This puts a staggering load on any attempt to provide on organized diabetic foot care service.

Increased plantar foot pressure is a leading cause of ulceration in the diabetic population. Healing of these ulcers requires adequate blood supply, control of infection, excellent wound care and 'offloading' or pressure redistribution of the ulcerative area. Out of all these factors, 'offloading' is a unique challenge in treating chronic wounds. There have been many techniques suggested for off-loading pressure from diabetic foot ulcers to promote faster healing, but most of them have been expensive instruments and techniques. Majority of the diabetic population in our country cannot afford these expensive techniques, which urges us to find out a cost effective economical off-loading device.

\section{Methodology}

This study was carried out in the Department of General Surgery, in Mahatma Gandhi Medical College \& Research Institute, Pondicherry during the period between October 2010 to March 2012. After obtaining Institutional Human Ethics Committee clearance, a total of 50 ambulant Diabetic patients with plantar foot ulcer were studied.

The patients were randomized by draw of lots and divided into two groups, of which 25 patients were offloaded(Group A) and 25 patients were not offloaded(Group B), and the size of the ulcers were compared.

After duly obtaining an informed consent, detailed history of all patients were taken, that included demographic data, occupation, symptomatology, duration of diabetes. A thorough clinical examination was done as a very important step to determine the size and depth of the ulcer, and peripheral pulses. Patients were also evaluated for other risk factors like obesity and hypertension. X-ray foot and pus culture were done. 
The ulcer size was measured with the help of graph plotted on transparent sheet. MANDAKINI ${ }^{1}$ device was adopted to offload Group A patients. A pair of used gloves was rolled as done for autoclaving, and placed over the adhesive surface of dynaplast and covered circumferentially with dynaplast. The edges were approximated by sharp pressure. The off-loading device was placed in respect to the site of the ulcer, proximal to the ulcer in case of distal fore foot lesions and distal to the ulcer in hind foot lesions. It acted as a soft air cushion and off-loads body weight. The number of gloves were increased based upon the body weight of the patient [Figure]. The device was changed every week, for 4-6 weeks.In addition to off-loading, the wounds were daily dressed and suitable antibiotics according to culture were administered. The Group B patients were treated with daily dressing and suitable antibiotics. Healing of ulcers were compared by measuring at 2 weeks, 4 weeks and 6 weeks of follow up.

The results of both groups were analysed and compared. Chi-square test was used for statistical analysis.

\section{Results}

Among the 50 patients studied, the youngest patient was 33 years old and the oldest was 70 . The mean age was 50.8 years. There were 9 patients in 31-40 age groups, 19 in 41-50, 13 in 51-60, 9 in 61-70. The highest incidence was in $5^{\text {th }}$ decade. There were $32(64 \%)$ male and $18(36 \%)$ female patients.

Of the 50 patients studied, $16 \%$ had diabetes for $<5$ years, $58 \%$ for $5-10$ years, $22 \%$ for $11-15$ years, and $2 \%$ for $16-20$ years, and $2 \%$ for $>20$ years.Among the 50 patients, $54 \%$ were smokers and $44 \%$ alcoholic. Peripheral pulses were noted in all patients.Among 50 patients, $62 \%$ had forefoot ulcers, $18 \%$ mid-foot ulcers and $20 \%$ hind-foot ulcers. Pus culture showed, Proteus sp., in $12(24 \%)$, E. coli in $12(24 \%)$, Pseudomonas sp.,in $5(10 \%)$, Klebsiella sp., in $5(10 \%)$, alpha haemolytic Streptococci in $4(8 \%)$, Staphylococcus aureus in $2(4 \%)$, MRSA in $1(2 \%), 9(18 \%)$ showed a polymicrobial growth pattern.X-ray of the foot showed osteomyelitis in $30 \%$ patients, of which $16 \%$ were males and $14 \%$ were females.

When evaluating the depth of the ulcer, of the 50 patients, $54 \%$ had deep fascia exposed, $28 \%$ had tendon exposed, and $18 \%$ had bone exposed. Among the 50 patients, $12 \%$ had ulcers $<5$ sq. cm, $68 \% 5-10$ sq. cm., $20 \%$ had ulcers $>11$ sq. $\mathrm{cm}$.

Among the 50, 6 patients had ulcers $<5$ sq.cm, 3 were off-loaded and 3 not off-loaded. At 2 weeks, $50 \%$ healing was noted in all patients from group A, whereas, 2 patients had $25-50 \%$ healing and 1 patient had less than $25 \%$ healing in group B. At 4 weeks, $75 \%$ healing was noted in all patients from group A, whereas, 2 patients had $75 \%$ healing and 1 patient had $25-50 \%$ healing in group B. At 6 weeks, $100 \%$ healing was noted in all patients from group A, whereas, 2 patients had $100 \%$ healing and 1 patient had $50-75 \%$ healing in group B. $\mathrm{P}$ value was 0.0498 for ulcer healing in 2 weeks and was significant . However $\mathrm{P}$ value for ulcer healing at 4 weeks and 6 weeks was 0.2733 for both and was not significant. [Table 1]

There were 34 patients who had ulcers between 5-10 sq. cm., of which 17 were in group A and 17 in B. At 2 weeks, $50 \%$ healing was noted in 13 patients and 25\% in 4 patients from group A, whereas, 12 patients had less than $25 \%$ healing, and 5 patients had $25 \%$ healing in group B. At 4 weeks, $75 \%$ healing was noted in 13 patients and $50 \%$ in 4 patients from group A, whereas, 12 patients had 25-50\% healing, and 5 patients had 50$75 \%$ healing in group B. At 6 weeks, $100 \%$ healing was noted in 13 patients and $75 \%$ in 4 patients from group A, whereas, 12 patients had $75 \%$ healing, and 5 patients had $100 \%$ healing in group B. P value was 0.0000 , 0.0000 , and 0.0060 at 2, 4, and 6 weeks respectively and were all significant.[Table 2]

There were 10 patients who had ulcers $>11$ sq. $\mathrm{cm}$. of which 5 were in group A and 5 in B. At 2 weeks, $50 \%$ healing was noted in 2 patients and $25 \%$ in 3 patients from group A, whereas, 4 patients had less than $25 \%$ healing, and 1 patients had $25 \%$ healing in group B. At 4 weeks, $50-75 \%$ healing was noted in 2 patients and $50 \%$ in 3 patients from group A, whereas, 4 patients had $25 \%$ healing, and 1 patient had $25-50 \%$ healing in group B. At 6 weeks, $100 \%$ healing was noted in 2 patients and 50-75\% in 3 patients from group A, whereas, 4 patients had $25-50 \%$ healing, and 1 patient had $75 \%$ healing in group B. P value was $0.0301,0.0184$, 0.0184 at 2,4 , and 6 weeks respectively and was significant.[Table 3]

While comparing the healing between two groups across all ulcer sizes at 6 weeks, in group A, 2 patients had 50-75\% healing, 5 patients had $75 \%$ healing and $100 \%$ healing was noted in 18 patients. However, in group B, 3 patients had 25-50\% healing, 2 patients had 50-75\% healing, 13 patients had 75\% healing and 7 patients had $100 \%$ healing. P value was 0.0225 and was significant. [Table 4] 
IV. Tables

Table 1 : Ulcer healing $<5$ sq.cm.

\begin{tabular}{|c|c|c|c|c|c|}
\hline \multirow{2}{*}{ Duration } & \multicolumn{2}{|c|}{$\begin{array}{c}\text { OFF LOADED } \\
\text { (Group A) }\end{array}$} & \multicolumn{2}{|c|}{$\begin{array}{c}\text { NOT OFF LOADED } \\
(\text { Group B) }\end{array}$} & \multirow{2}{*}{ P Value } \\
\hline & $\begin{array}{l}\text { No .of. Pts } \\
\text { (3) }\end{array}$ & $\begin{array}{c}\text { Healing } \\
\text { Rate } \\
(\%)\end{array}$ & $\begin{array}{l}\text { No .of. pts } \\
\text { (3) }\end{array}$ & $\begin{array}{c}\text { Healing } \\
\text { Rate } \\
(\%)\end{array}$ & \\
\hline 2 Weeks & $\begin{array}{l}3 \\
-\end{array}$ & $\begin{array}{c}50 \\
-\end{array}$ & $\begin{array}{l}2 \\
1\end{array}$ & $\begin{array}{c}25-50 \\
<25\end{array}$ & 0.0498 \\
\hline 4 Weeks & $\begin{array}{l}3 \\
-\end{array}$ & $\begin{array}{c}75 \\
-\end{array}$ & $\begin{array}{l}2 \\
1\end{array}$ & $\begin{array}{c}75 \\
25-50\end{array}$ & 0.2733 \\
\hline 6 Weeks & $\begin{array}{l}3 \\
-\end{array}$ & $\begin{array}{c}100 \\
-\end{array}$ & $\begin{array}{l}2 \\
1\end{array}$ & $\begin{array}{c}100 \\
50-75\end{array}$ & 0.2733 \\
\hline
\end{tabular}

Table 2 :Ulcer healing 5-10 sq.cm.

\begin{tabular}{|c|c|c|c|c|c|}
\hline \multirow[b]{2}{*}{ Duration } & \multicolumn{2}{|c|}{$\begin{array}{l}\text { OFF LOADED } \\
(\text { Group A })\end{array}$} & \multicolumn{2}{|c|}{$\begin{array}{l}\text { NOT OFFLOADED } \\
(\text { Group B })\end{array}$} & \multirow[b]{2}{*}{ P Value } \\
\hline & $\begin{array}{l}\text { No .of. Pts } \\
\text { (17) }\end{array}$ & $\begin{array}{c}\text { Healing Rate } \\
(\%)\end{array}$ & $\begin{array}{c}\text { No .of. pts } \\
\text { (17) }\end{array}$ & $\begin{array}{c}\text { Healing } \\
\text { Rate } \\
(\%)\end{array}$ & \\
\hline 2 Weeks & $\begin{array}{l}13 \\
4\end{array}$ & $\begin{array}{l}50 \\
25\end{array}$ & $\begin{array}{l}12 \\
5\end{array}$ & $\begin{array}{c}<25 \\
27\end{array}$ & 0.0000 \\
\hline 4 Weeks & $\begin{array}{l}13 \\
4\end{array}$ & $\begin{array}{l}75 \\
50\end{array}$ & $\begin{array}{l}12 \\
5\end{array}$ & $\begin{array}{l}25-50 \\
50-75\end{array}$ & 0.0000 \\
\hline 6 Weeks & $\begin{array}{l}13 \\
4\end{array}$ & $\begin{array}{l}100 \\
75\end{array}$ & $\begin{array}{l}12 \\
5\end{array}$ & $\begin{array}{c}75 \\
100\end{array}$ & 0.0060 \\
\hline
\end{tabular}

Table 3 : Ulcer healing $>11$ sq.cms

\begin{tabular}{|l|l|c|l|c|c|}
\hline & \multicolumn{2}{|c|}{$\begin{array}{c}\text { OFF LOADED } \\
\text { (Group A) }\end{array}$} & \multicolumn{2}{c|}{$\begin{array}{c}\text { NOT OFF LOADED } \\
\text { (Group B) }\end{array}$} & \\
\hline Duration & $\begin{array}{c}\text { No.of. Pts } \\
(\mathbf{5})\end{array}$ & $\begin{array}{c}\text { Healing Rate } \\
(\boldsymbol{\%})\end{array}$ & $\begin{array}{c}\text { No .of. pts } \\
(\mathbf{5})\end{array}$ & $\begin{array}{c}\text { Healing Rate } \\
(\boldsymbol{\%})\end{array}$ & P Value \\
\hline & 2 & 50 & 4 & $<25$ & 0.0301 \\
\hline Weeks & 3 & 25 & 1 & 25 & 0.0184 \\
4 Weeks & 2 & $50-75$ & 4 & $25-50$ & \\
\hline & 2 & 50 & 1 & $25-50$ & 0.0184 \\
6 Weeks & 3 & 100 & 4 & 75 & \\
\hline
\end{tabular}

Table 4: Healing of all ulcers at 6 weeks (Cumulative)

\begin{tabular}{|c|c|c|c|c|}
\hline \multicolumn{2}{|c|}{$\begin{array}{l}\text { OFFLOADED } \\
\text { (Group A) }\end{array}$} & \multicolumn{2}{|c|}{$\begin{array}{c}\text { NOT OFF LOADED } \\
\text { (Group B) }\end{array}$} & \multirow[b]{2}{*}{$\begin{array}{c}\text { P } \\
\text { VALUE }\end{array}$} \\
\hline $\begin{array}{c}\text { NO.OF } \\
\text { PATIENTS }(\%)\end{array}$ & $\begin{array}{c}\text { HEALING } \\
\text { PERCENTAGE }\end{array}$ & $\begin{array}{c}\text { NO. OF } \\
\text { PATIENTS(\%) }\end{array}$ & $\begin{array}{c}\text { HEALING } \\
\text { PERCENTAGE }\end{array}$ & \\
\hline $0(-)$ & $<25$ & $0(-)$ & $<25$ & \multirow{6}{*}{0.0460} \\
\hline $0(-)$ & $25-50$ & $3(12 \%)$ & $25-50$ & \\
\hline $2(8 \%)$ & $50-75$ & $2(8 \%)$ & $50-75$ & \\
\hline $5(20 \%)$ & 75 & $13(52 \%)$ & 75 & \\
\hline $18(72 \%)$ & 100 & $7(28 \%)$ & 100 & \\
\hline 25 & & 25 & & \\
\hline
\end{tabular}

\section{Discussion}

Among patients with diabetes, roughly about $15 \%$ develop a foot ulcer. Diabetic foot is a complex pathology with narrow window of opportunity to work. If not dealt with right approach ends up with amputation. It needs special care. A non-healing ulcer on plantar aspect can lead to severe infection. Eighty percent of diabetic foots are neuropathic in India and this leads to loss of sensation in foot and offloading is the major solution for healing of plantar lesions.

In this study, 25 patients with diabetic foot ulcer were treated by off-loading device (Mandakini) and 25 patients by not off-loading and the healing rates were compared. 
Mean age in our study is 50.84 years, whereas in a study by Sicco A. Bus et al $^{2}$, the mean age was 59.1 years. The mean age in our study is slightly lower. Patients in developing countries do not give much attention to foot care, they do not wear footwear outdoors, and these coupled with the economic factors may be responsible for the lower mean age in our study. Prevalance of diabetic foot ulcers is higher in males, when compared to females.

The duration of diabetes also plays a role in the formation of ulcer and the incidence of lower extremity amputation is more in patients who have diabetes for more than 5 years ${ }^{3,4,5,6,7}$. Longer the duration of diabetes, higher are the odds of developing a non-healing ulcer. Mehamudet al. ${ }^{8}$ of Pakistan has reported that out of 120 patients, majority of patients who underwent amputation had diabetes more than 10 years $(\mathrm{p}<0.05)$.

In our study, $54 \%$ of patients are smokers and $44 \%$ consumed alcohol. In another study carried out at our institute by Karthik $\mathrm{P}$ et al. ${ }^{9}$ found smoking and alcohol consumption is linked to higher incidence of foot ulcers in diabetics, and was a statistically significant risk factor for amputation in patients with diabetic foot ulcers.

The most frequently cultured microorganisms in our study are Proteus and E.coli both accounting to $24 \%$, following which polymicrobial infection is present in $18 \%$ of patients. Caballero E, Frykberg RG et $\mathrm{al},{ }^{10}$ reportedPolymicrobial infections predominate in severe diabetic foot infections and include a variety of aerobic gram-positive cocci, gram-negative rods, and anaerobes.

The interventions considered for plantar ulcer in diabetic patients can be four groups of techniques: casting technique, foot wear related techniques, surgical off-loading techniques and other off-loading techniques like, bed rest, wheel chairs, walkers, off-loading dressing, felted foam or padding and plugs.Among the casting techiniques Total contact cast(TCC) has shown to heal higher number of plantar ulcers, at a faster rate, but the patients are much less active ${ }^{11}$.The results of surgical techinique are not conclusive. A randomised control study by Piaggesi A. et $\mathrm{al}^{12}$ shows a lower ulcer recurrence rate after combined surgical procedures, compared to conservative off-loading treatment. However, a short study of arthroplasty in addition to TCC has shown no difference in ulcer healing compared to TCC alone ${ }^{13}$.

Ezio Faglia ${ }^{14}$ compared the use of Stabil-D off-loading device versus the conventional TCC and found that the use of Stabil-D is as effective as use of a TCC in the treatment of neuropathic plantar forefoot ulcers. He concluded that Stabil D off-loading device had better patient compliance and was equally effective when compared to TCC. Bus SA. et $\mathrm{al}^{15}$ in a review article concludes, more studies are needed to confirm the effectiveness of different techiniques in prevention and healing of foot ulcer and to reduce plantar pressure. The effectiveness of different techiniques and devices in ulcer healing always depends on the adherence to treatment by the patient, even most effective device will be a failure if it is not worn properly.

The other important factor is the cost of foot wear and devices, especially to patients in developing countries. The cost of the Stabil-D device was Rs $8972(€ 130)$ each plus Rs 1380(€20) for the Modus plantar sole. The cost of the TCC was Rs $5038(€ 73.50)$ per cast (Rs 1518(€22) for the stockinet, Rs 276(€4) for the Microfoam, and Rs 3243(€47.5) for the bandages). For a very obese patient an extra bandage was required, increasing the cost to $€ 89.5$. Twenty-two off-loading devices were applied to patients in the Stabil-D group, and total costs were $€ 3,300.00$. A total of 91 casts were applied to patients in the TCC group for a total cost of $€ 6,688.50$. The MANDAKINI off-loading device costs about Rs. 150 (€2) for 6 weeks of treatment per patient. The healing rates mentioned earlier were very impressive, with this extremely economical device. Also the device is very well accepted by the patients, the compliance was very encouraging. This goes on to show that a simple, economical, easy to use and easily duplicable device is as effective, if not more, when compared to the available expensive devices.

\section{Conclusion}

The Mandakini off-loading device is cost effective for developing countries like us. The healing rates mentioned earlier were very impressive, with this extremely economical device. Also the device was very well accepted by the patients, the compliance was very encouraging. This shows that a simple, economical, easy to use and easily duplicable device is as effective, if not more, when compared to the available expensive devices.

\section{Limitations}

This study may not reflect all the aspects of management of diabetic foot ulcers, further, the series was small and follow up was for a short period in most of the cases. A larger study spanning over longer time period is required to draw definitive conclusions. 

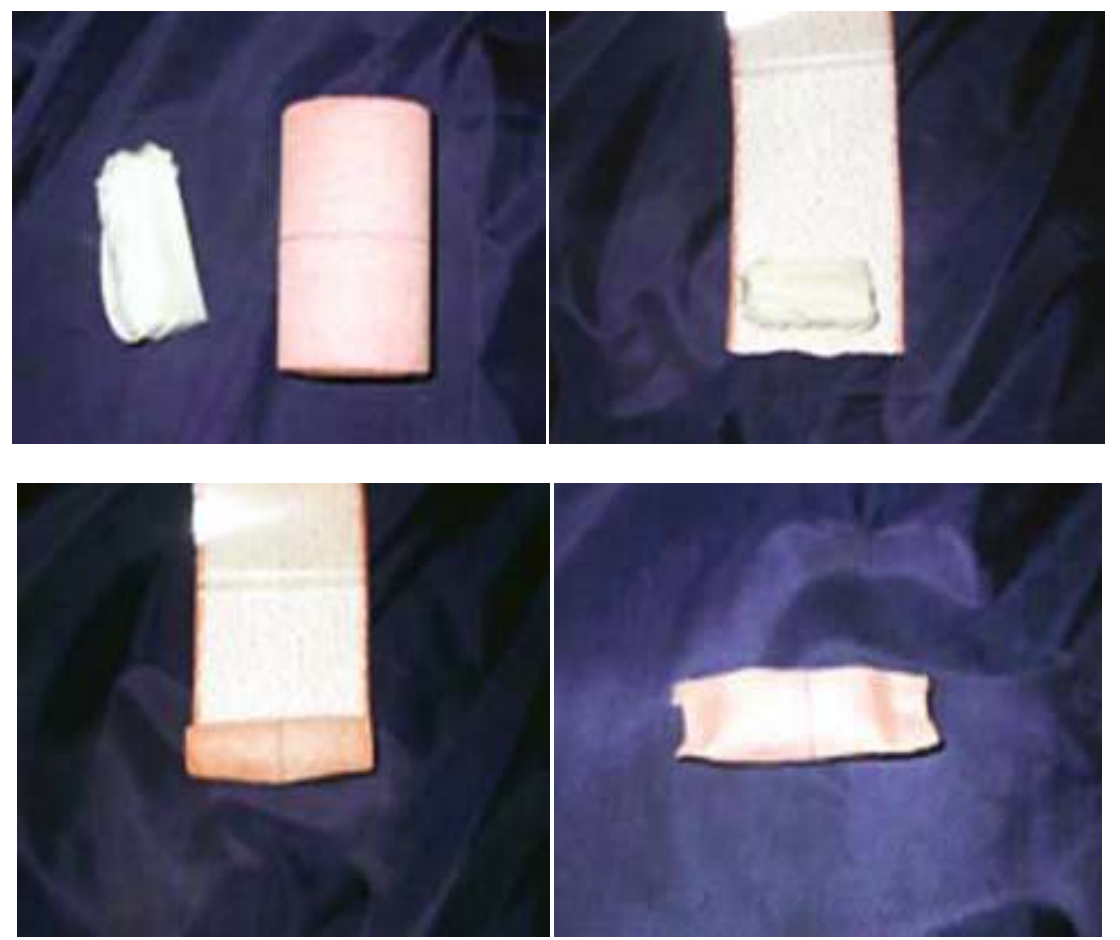

Mandakini device

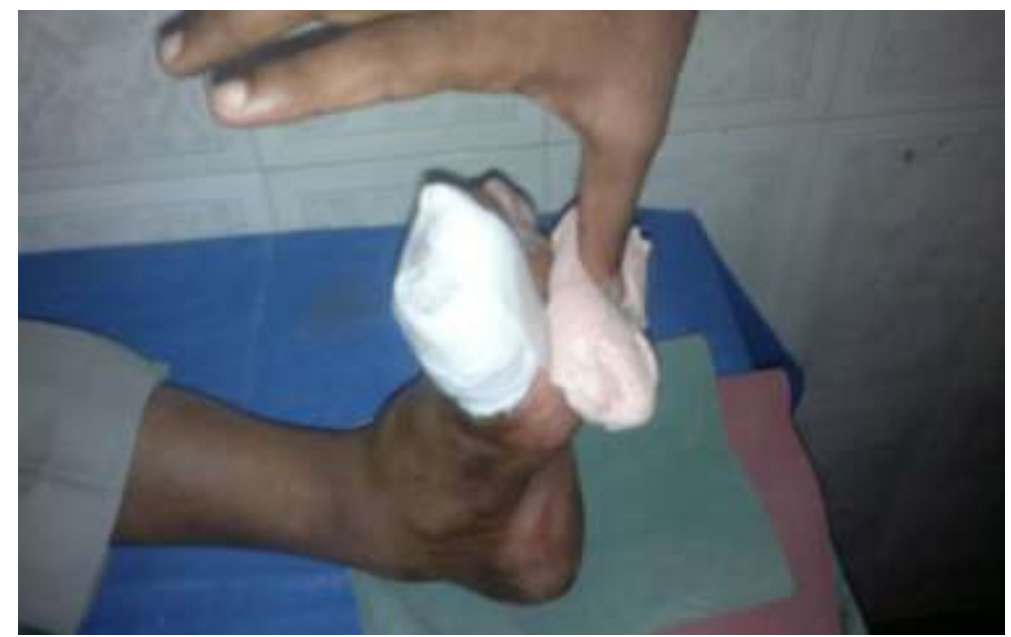

Mandakini device being placed.

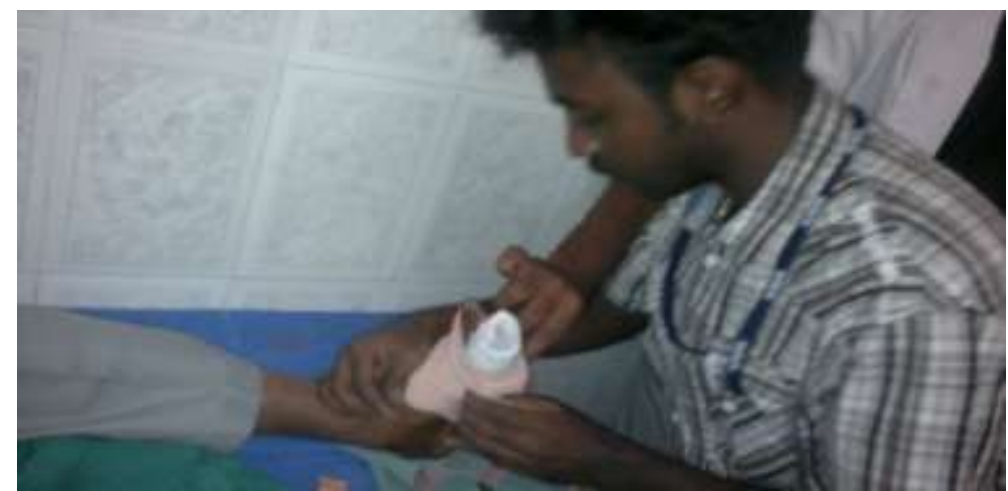

Fixing Mandakini device 


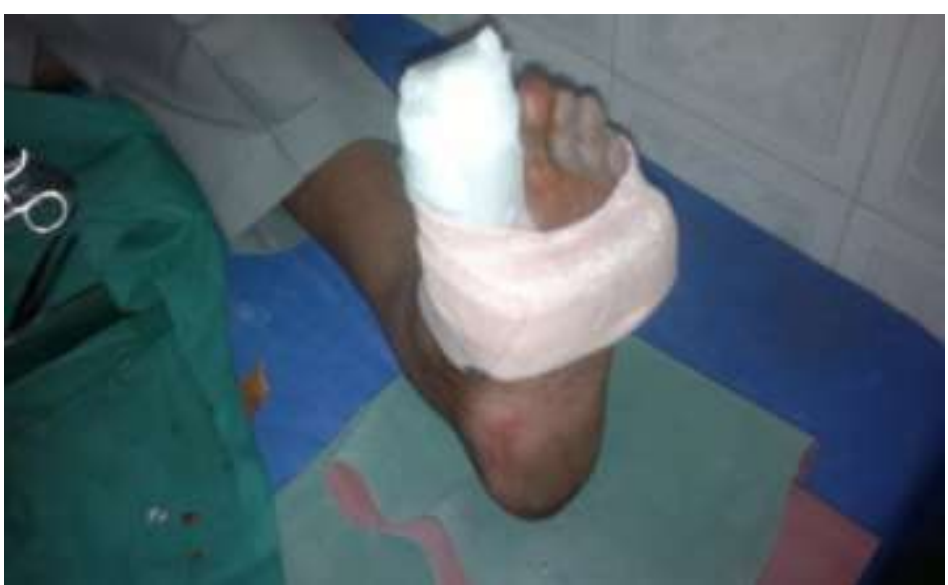

Final position of Mandakini device

\section{References}

[1]. Sunil V.Kari, et al., The economical way to off-load diabetic foot ulcers (Mandakini off-loading device), Indian J Surg. 2010 Apr; 72(2):133-134.

[2]. SICCO A .Evaluation and Optimization ofTherapeutic Footwear for NeuropathicDiabetic Foot Patients Using In-ShoePlantar Pressure Analysis. Diabetes Care 2011 34:1595-1600

[3]. Al-Maskari F, El-Sadig M. Prevalence of risk factors for diabetic foot complications. BMC. Fam. Pract.2007; 8:59.

[4]. Alwakeel JS, Al-Suwaida A, Isnani AC, Al-Harbi A, Alam A. Concomitant macro and microvascular complications in diabetic nephropathy. Saudi Journal of Kidney Dis. Transpl. 2009; 20(3): 402-09.

[5]. Krittiyawong S, ANagarmukos c, Benjasuratwong Y, Rawdarce P, Leelawatana R, Kosachunhanun N, Plengvidhya N, Deerochanawong C, Suwanwalaikorn S, Pratipanawatr T, Chetthakul T, Mongkolsomlit S, Bunnag P. Thailand diabetes registry project : prevalence and risk factors associated with lower extremity amputation in Thai diabe5tics. Med. Assoc. Thai. 2006; 89(1): $43-48$.

[6]. Leelawattana R, Pratipanawatr T, Bunnag P, Kosachunhanum N, Suwanwalaikorn S, Krittiyawong S, Cheetthakul T, Plengidhya N, Benjasuratwong Y, Deerochanawong C, Mongkolsomilt S, Ngamukos C, Rawdarce P. Thailland diabetes registry project: prevalence of vascular complications in long - standing type 2 diabetes. Journal of Med. Assoc. Thai. 2006; 89(1): 54-59.

[7]. Elliott J. Tesfave S, Chaturvedi N. Gandhi RA, Stevents LK, Emery C, Fuller JH. Large fibre dysfunction in diabetic peripheral neuropathy is predicted by cardiovascular risk factors. Diabetes Care 2009; July 8.

[8]. Mehmud K, Akhtar St, Talib A, Talib A, Abbasi B, Siraj-ul-Salekeen, Naqvi IH Clinicaprofile and management outcome of diabetic foot ulcers in a tertiary care hospital. J. Coll. Physicians Surg. Pak. 2008; Jul: 18(7): 408-12.

[9]. Karthik P, Risk factors for lower extremity amputation in diabetic foot ulcers. Dissertation submitted to Pondicherry University, 2009.

[10]. Caballero E, Frykberg RG. Diabetic foot infections. J Foot Ankle Surg. 1998;37:248-55

[11]. Muller MJ, Diamond JE, Sinacore DR, et al. Total contact casting in treatment of diabetic plantar ulcers, controlled clinical trial.Diabetes care 1989; 12:384-388.

[12]. PiaggesiA,Schipani E, Campi F, et al. Conservative surgical approach versus non-surgical management for diabetic neuropathic foot ulcers; randomized trial. Diabet.Med 1998; 15:412-417.

[13]. Amstrong DA, Lavery LA, Vazguez JR, et al. Clinical efficacy of the first metatarso phalangeal joint,arthroplasty as a curative procedure for hallux interphalangeal joint wounds in patients with diabetics. Diabetes care 2003; 26:3284-3287.

[14]. EzioFaglia, Md. Effectiveness of Removable Walker Cast Versus Nonremovable Fiberglass Off-Bearing Cast in the Healing of Diabetic Plantar Foot Ulcer. Diabetes Care 2010 33:1419-1423.

[15]. Bus SA, Valk GD, VanDeursen, et al, The effectiveness of footwear and off-loading intervention to prevent and heal foot ulcers and reduce plantar pressure in diabetes: a systemic review. Diabetes mellitus Rev.2008;24(suppl 1): S162-S180. 